Margaret Gilbert

\title{
Two Approaches to Shared Intention: An Essay in the Philosophy of Social Phenomena
}

\begin{abstract}
Drawing on earlier work of the author that is both clarified and amplified here, this article explores the question: what is it for two or more people to intend to do something in the future? In short, what is it for people to share an intention? It argues for three criteria of adequacy for an account of shared intention (the disjunction, concurrence, and obligation criteria) and offers an account that satisfies them. According to this account, in technical terms explained in the paper, people share an intention when and only when they are jointly committed to intend as a body to do such-and-such in the future. This account is compared and contrasted with the common approach that treats shared intention as a matter of the correlative personal intentions, with particular reference to the work of Michael Bratman.
\end{abstract}

\section{Prologue: Analytic Philosophers on Social Phenomena}

In the late 1980s and early 1990s analytic philosophy took an important new turn: it began to take a sustained and focused look at the nature of the social world and the distinctive phenomena that it includes. ${ }^{1}$ There have, of course, been extremely important studies of particular social phenomena within analytic philosophy that predate this period, not to speak of studies outside that philosophical orientation. Influential examples of such earlier work in analytical philosophy are H. L. A. Hart's discussion of social rules in The Concept of Law, and David K. Lewis's game-theoretical account of social convention. ${ }^{2}$

These two works were in a broad sense individualistic in their approach. Just as, in the study of demonstratives, the analytic tradition had focused on ' $\mathrm{I}$ ' and not at all on 'we', so the theories of these authors could be fully represented in terms of 'I' rather than 'we'. Thus, according to Hart, there is a social rule in some population if and only if I, on the one hand, and you, on the other, have certain attitudes (often for a multitude of different 'I's).

\footnotetext{
1 Two points of clarification: (1) I do not take the distinction between 'analytic' and other kinds of philosophy to be clear-cut. (2) The social world on which philosophers have so far focused is that of human beings rather than non-human creatures. I maintain that focus in this essay.

2 Hart 1961; Lewis 1969. In my own work I focus on Hart's discussion in Gilbert 2000, ch. 5; and on Lewis in many places including Gilbert 1989, ch. 5 and, most recently, Gilbert 2008.
} 
There were also works that went beyond the 'I' perspective. These are exemplified in the writings of Charles Taylor, who was influenced by the continental tradition. Using helpful concrete examples, Taylor advanced the important argument that in addition to the possibility that some fact is 'common knowledge' between you and me - roughly, I know it, you know it, I know that you know it, and so on - there is the further possibility that it is 'entre nous', 'between us', 'in public space'. ${ }^{3}$ Though the quoted phrases are not self-explanatory, Taylor's general message is clear. There is a way in which people can relate to one another with respect to their knowledge of some fact that goes beyond the 'I' perspective of common knowledge and somehow pertains to 'us'. ${ }^{4}$ Wilfrid Sellars had earlier appealed to thoughts couched in terms of 'us' rather than 'me' (Sellars 1963).

In saying that a new turn was taken after this, I mean that the philosophy of social phenomena, under various labels, began to attract large numbers of new researchers, from doctoral students and junior faculty to senior members of the profession. It is possible that this was in part because in the few years around 1990 a certain critical mass was reached in terms of distinct perspectives within the field.

I published 'Modeling Collective Belief' in 1987 and my book On Social Facts in $1989 .{ }^{5}$ This work offered novel accounts of a wide range of social phenomena including group languages, acting together, social groups, collective belief, and social convention. In 1990 John Searle published an article on 'collective intentions and actions'. Among other things he criticizes an article by Raimo Tuomela and Kaarlo Miller entitled 'We-Intentions', published in 1988. ${ }^{6}$ Michael Bratman published his articles 'Shared Co-operative Activity' in 1992, and 'Shared Intention' in 1993, citing the work of Searle, Tuomela and Miller, and myself. ${ }^{7}$

Following this period many new articles and books were written in the area. There was significant interest in the topic of collective belief, but topics in the area of acting together have so far predominated. That topic was addressed in all of the above mentioned works, and was, indeed, the main focus of all but my own.

3 See Taylor 1985. On 'common knowledge' see Lewis 1969; for a proposal of my own see Gilbert 1989, ch. 4. A good general survey of the often quite technical literature is to be found in Vanderschraaf/Sillari 2007.

4 This part of Taylor's work was an important influence on my own thinking. See Gilbert 1989, preface. Though there I see common knowledge as playing a significant role in human sociality, I saw a more central role for it in the doctoral dissertation 1978 of the same title. The latter is, to my knowledge, the first attempt within analytic philosophy to attempt a general theory of social phenomena in the human world. Central references in the book were the sociologists Emile Durkheim, Georg Simmel and Max Weber, and the philosophers Peter Winch and David Lewis. The work of all three sociologists, in particular that of Simmel, can reasonably be thought of as comprising an important part of the philosophy of social phenomena.

5 As it happens, the article was written after the book went to press.

6 Tuomela/Miller 1988 maintains the basic thesis of Tuomela 1984, a substantial treatise which cites Sellars' work as a major influence, along with material in Rosenberg 1980, also inspired by Sellars. More attention has been paid in the literature to the article, which, the authors say, maintains the basic thesis of the book, also represented in Tuomela/Miller 1985. See Tuomela/Miller 1988, 388n 2.

7 Bratman 1999, 9n14, notes the particular influence of Searle 1990. 
Two important aspects of the development of this general area of analytic philosophy are as follows. First, it is clearly pertinent to several other fields within philosophy including political philosophy, the philosophy of law, and ethics. For example, theories of acting together can be expected to throw light on the topic of collective moral responsibility. ${ }^{8}$

A second important aspect of the development of this general area of analytic philosophy has been the interest taken in it by social scientists and others in a variety of fields. These fields include experimental social psychology, economics, management science, communication theory, political science, developmental psychology, anthropology, along with primatology and artificial intelligence.

This interest is not surprising, if only for reasons that Max Weber articulated at the turn of the $19^{\text {th }}$ century. Centrally, the social sciences are concerned with processes involving human action. There is then a need to understand, with as much articulation as possible, the concepts that inform the actions in question. At least some of those engaged in the philosophy of social phenomena, myself included, aim precisely to articulate pertinent everyday concepts such as the concept of acting together. Their accounts may be viewed in some such light: they propose that acting together, say, as conceived by non-theorists who see themselves as so acting, amounts to such-and-such. Those who do not see their aim in precisely this way may yet, in their accounts of acting together and so on, go some way to articulate such vernacular concepts. And all may direct the community of scientists and scholars to important phenomena that might otherwise fail to attract its attention. ${ }^{9}$

Sometimes the account of a phenomenon such as acting together that has been produced by a philosopher has been directly applied to an issue within another discipline. ${ }^{10}$ This process may itself constitute a contribution to the philosophical conversation. And theorists in other fields have sometimes entered that conversation more directly. ${ }^{11}$

This essay will focus on a particular social phenomenon, which I refer to here as 'shared intention'. ${ }^{12}$ I contrast my own approach to it with another, very common perspective which, I argue, is not apt to produce a satisfactory account of this phenomenon. As will emerge, the topic is rich and complex. Though the discussion that follows is intended to be relatively self-contained, it is inevitably sketchy in places. Where pertinent I sometimes cite more extended discussions of important points.

I first discussed the topic of shared intention, specifically, in 'What is it for Us to Intend?', having prepared the ground for it in On Social Facts, where my

\footnotetext{
${ }^{8}$ For a recent volume devoted to this relationship see French (ed.) 2006. Other pertinent topics include the problem of political obligation. See e.g. Gilbert 2006.

${ }^{9}$ Cf. Gilbert 2008 on the distinct accounts of social convention offered by David Lewis and myself.

10 See, for instance Bagozzi/Dholakia 2006.

11 See, e.g., economists Sugden 1993, also Sugden/Gold 2007; Davis 2003; Bacharach 2006; Bardsley 2007.

12 Other equally if not more appropriate phrases that have been used in the literature are 'collective intention' and 'joint intention'.
} 
focus was on acting together and shared readiness to act. ${ }^{13}$ Further material has amplified important aspects of the discussion. ${ }^{14}$ The present discussion will pull together central elements of this earlier work while extending and clarifying it in various ways. ${ }^{15}$

\section{Shared Intention}

The technical phrase 'shared intention', now in common use by philosophers, comes from Michael Bratman (Bratman 1993). It is best to specify how I shall understand it here. I do so by reference to an imaginary dialogue. For the sake of simplicity, here as elsewhere in this paper, I use an example of shared intention involving two people. ${ }^{16}$

Suppose Alice asks Ben 'What are you doing this afternoon?' and Ben, gesturing towards Celia, replies 'We're going shopping.' If Alice were -improbably - to respond 'I see: you intend to go shopping and Celia intends to go shopping', Ben might irritably reply 'No, no: we intend to go shopping!'

In this paper I construe the phrase 'shared intention' roughly as follows: a shared intention is what people refer to when - as in Ben's case - they utter everyday sentences of the form 'We intend to do A', 'We're going to do A', and the like, and are not using them elliptically for 'We both intend to do A' or 'We all intend to do A', and so on. ${ }^{17}$ I shall refer to such sentences, when used to refer to a shared intention, as shared intention sentences.

Shared intention sentences can take a variety of forms. For example, instead of taking the form 'We intend to do A', and so on, they may take the form 'Our intention is to do A', and so on. They may also take the form 'We intend that p' e.g. 'We (Diane and Ed) intend that Fern attend the best school in town'. I shall focus here on the 'intend to' form of shared intention sentence.

Shared intention sentences may explicitly or implicitly refer to particular individuals as parties to the shared intention. Or they may explicitly or implicitly refer to individuals insofar as they possess certain general features including relational features. Again for the sake of simplicity, my focus in this article will be on the kind of shared intention sentence that refers to particular individuals, and the corresponding shared intentions. ${ }^{18}$

\footnotetext{
13 See Gilbert 1997; 1989. Also e.g. Gilbert 1990.

14 E.g. Gilbert 2003 and 2006, chapters 6 and 7.

15 Special features of this discussion in relation to Gilbert 1997 include: an explicit focus on future-directed shared intentions; emphasis on the problems three plausible criteria of adequacy pose for an account of shared intention in terms of corresponding personal intentions; expansion of my previous argument for the disjunction criterion, a further articulation of obligation criterion, and further discussion of the ability of a plural subject or joint commitment account to satisfy it (see the text below for explanation of technical terms used in this note).

16 Cf. Bratman 1993. The perspective on shared intention that I advocate has no problem with larger scale cases. See, e.g., Gilbert 2006, ch. 8.3, which discusses a broader range of phenomena but whose general approach can be applied to the case of shared intention.

17 The answer could in principle be disjunctive.

18 My perspective on shared intention can accommodate cases involving populations individuated by one or more common features, something that is necessary when dealing with what
} 
Philosophers of action who are not concerned with shared intention specifically distinguish between intentions that regard the future and intentions in acting - such as my intention in raising my arm precisely to raise it. In this paper I am concerned with shared intentions that regard the future, rather than shared intentions in acting. In what follows I shall take this as read.

In at least some cases of future-directed intentions, whether shared or not, it is natural also to speak of plans. I take it that, indeed, if one plans to do something in the future, then one intends to do it in the sense of 'intention' pertinent here. ${ }^{19}$

Intuitively an agreement between the parties is sufficient to bring a shared intention into being. Thus one morning Gina may say to Harry 'Shall we go to the library this afternoon?' and Harry may reply 'Sure'. Gina might now properly say to a third party, of Harry and herself 'We intend to go to the library this afternoon', in the shared intention sense of 'We intend [...]'. In at least this kind of case one might also speak in terms of planning. Thus, in the example, Gina might equally well say to the third party 'We plan to go to the library this afternoon'.

A future-directed shared intention need not stem from what is strictly speaking an agreement between the parties. In saying this I mean not to rule out the possibility that something akin to an agreement, strictly speaking, may be involved in the genesis of all shared intentions. In what follows when I write of 'an agreement' I should be understood to be talking about an agreement, strictly speaking.

Here is an example of the formation of a shared intention without an agreement between the parties. In late spring Isobel is organizing a summer trip for her students in which they will work in teams helping the townspeople in local towns recently devastated by floods. She puts on a table a list of assignments, each for two people to accomplish together, and asks each student to sign up for one of these assignments. Jake signs up to go to Quiet Harbor, and so does another student, Kristen, who has not spoken to him before. Standing by the table, they start to talk about how they will help the people of Quiet Harbor. I take it that at some point in this process Jake and Kristen come to share an intention to help the people of Quiet Harbor that summer, though they have not made an agreement with one another to help them.

Clearly, though understanding agreements should help us to understand shared intention, understanding shared intention is not simply a matter of understanding agreements.

Shared intentions and the actions that proceed from them can be significant forces for both good and evil: we can intend to save the world, and we can intend to destroy it. Whatever we intend, we may succeed in doing. For practical

Scott Shapiro has referred to as 'massively shared intentions', that is, the shared intentions of very large populations. On this see Gilbert 2006, ch. 8.3.

19 Bratman 1987, 29, offers a 'planning theory' intention and describes plans (as he conceives of them) as 'intentions writ large'. This implies, I take it, that plans and intentions do not differ in substance. 
purposes, it would be well to understand what such intentions amount to, as it is good to understand all such forces.

\section{The Personal Intentions Perspective}

In addition to the undoubted practical importance of shared intention, there is a more theoretical reason for caring about it. Shared intention sentences - though completely commonplace - may seem to raise a squarely philosophical puzzle.

On the face of it, one who says, for instance, 'Larry and Meg intend to paint the living room tomorrow' ascribes an intention to Larry and Meg, as opposed to Larry, on the one hand, and Meg, on the other. One may think that this cannot be right - things cannot be as they seem.

One may well think this if one assumes that the only intentions in the human domain are intentions of single human beings as opposed to intentions of two or more human beings, such as the putative intention of Larry and Meg. Perhaps one makes this assumption because one thinks that only a being with some feature possessed by individual human beings and not possessed by two or more human beings - a mind, perhaps, or consciousness, or a brain - can have intentions. In other terms, an intention must inhere in a mind, consciousness, or a brain (see, e.g., Searle 1990).

Suppose we refer to the intention of a single human being as a singularist intention. One may believe, with Wilfrid Sellars, for instance, that singularist intentions are not always personal intentions, that is, intentions expressible by sentences of the form 'I intend [...]'. ${ }^{20}$ One may yet think that in the human domain intentions of whatever kind are correctly ascribable only to a given individual human being. I shall call this the singularist assumption about intentions, or, for short, the singularist assumption. ${ }^{21}$ If it is true, either shared intention sentences are false, or they are not what they seem.

This assumption can be questioned in light of the prevalence of shared intention sentences. To be sure, a singularist intention and an intention ascribable to two or more human beings - to 'us' or, correlatively, 'them' — will have different substrata. One can accept this without being forced to deny that the latter kind of intention is possible. Perhaps, after all, an intention need not inhere in a feature of individual human beings that 'we' or 'they' inevitably lack. ${ }^{22}$

In theorizing about shared intention it is best, I suggest, to set aside the singularist assumption. That leaves us with the question: how best are we to understand what shared intention amounts to?

\footnotetext{
20 Sellars 1963, 203; also Searle 1990. Both invoke intentions of individuals expressible by sentences of the form 'We intend [...]'. I have critically discussed Searle's approach to shared intention (insofar as he does approach it) in Gilbert 2007. See also (on Searle and others including Bratman and Tuomela and Miller) Gilbert 1998.

21 I coined the term 'singularism' in Gilbert 1989, for related purposes.

22 For concordant discussion relating to the ascription of beliefs to two or more persons, as opposed to individual people, see Gilbert 2002a. I take Bratman's statements on his theory of shared intention 1993, 107, to be in the spirit of these remarks. He says, e.g. "shared intention, as I understand it, is not an attitude in any mind". (I take it he believes that shared intention is nonetheless intention; it is, in particular, our intention.)
} 
Recall that I am focusing in this paper on cases in which a shared intention is ascribed to two or more particular individuals as such. In addition, I focus on cases in which there are no pertinent authority-relations between the parties. In particular, neither is in a position to stipulate a shared intention for the two. These may or may not be the most basic cases from a genealogical point of view, but, at the least, they are commonplace cases that it is important to understand.

It is natural to proceed by asking what shared intention amounts to at the individual level. What must each of us think or have thought, do or have done, and so on, in order that we intend to do such-and-such? Can a set of individually necessary and jointly sufficient conditions for a shared intention be given along these lines? In other words, can one give what I shall refer to as an account of shared intention in these terms? It is possible, of course, that the best we can come up with is a set or sets of conditions sufficient for a case of shared intention, as opposed to a set of conditions that are individually necessary and jointly sufficient. The latter would be most satisfying, however, so it is worth proposing as an initial target.

It is not clear how many theorists who work in the philosophy of social phenomena have been concerned with shared intention in precisely my sense. ${ }^{23}$ Even when their focus is the same, they may not aim to give more than sufficient conditions for a case of shared intention, or, whatever their initial aim, they may not claim to have given more than sufficient conditions. ${ }^{24}$ Whatever precisely a given theorist's aim, one can usefully consider whether a given account of what is referred to by its author as 'shared intention', 'collective intention', or something with a similar flavor, does in fact constitute an account of shared intention as I have just characterized such an account. That will be my procedure here.

It is standard to proceed in terms of a set of singularist-intentions - a set of intentions ascribed, seriatim, to different human individuals. Within this framework, a popular option is what I shall call the personal intentions perspective, according to which the singularist-intentions in question are personal intentions. This is probably the most prevalent perspective among theorists. ${ }^{25}$ That is hardly surprising. An appeal to personal intentions, in contrast to an appeal to

23 Bratman 1993 opens with a reference to what I am calling shared intention sentences with the implication that these fix the topic (98). To this extent we are on the same page. He then moves to the question "What do shared intentions do, what jobs do they have in our lives?" (99) and couches his aim ("what we want to know") (99) as that of finding an appropriate complex of the attitudes of each participant whose proper functioning would do those jobscoordinating our personal plans and actions and providing a framework for bargaining - since "we would have reason to identify shared intention with this complex" (100).

24 Cf. Velleman 1997. Though clearly preferring to have developed a set of individually necessary and jointly sufficient conditions, Bratman 1993 allows that the conditions he has proposed may be sufficient but not necessary for a case of shared intention.

25 Among those who do not adopt it in addition to Sellars 1963 and Searle 1990 is Bardsley 2007 who offers a version of Searle's approach. His particular interest is in how people might solve such coordination problems as the 'Hi-Lo' game without prior interaction. On the latter, and Searle, Bratman, and Tuomela and Miller's work in relation to it, see also Gold/Sugden 2007. My own sense of 'Hi-Lo' is that one does not need to bring 'we' thoughts in to explain why people tend to go for $\mathrm{Hi}$, though classical game-theory may not mandate it. That is a topic for another occasion, though see Gilbert 1981. 
any other form of singularist-intention, is an appeal to something relatively well studied and familiar from outside the philosophy of social phenomena. ${ }^{26}$

Among theories that adopt a personal intentions perspective, the most prominent and influential is that of Michael Bratman. In its initial presentation in 1993 it ran roughly as follows:

"With respect to a group consisting of you and me, and concerning joint activity, J, we intend to $J$ if and only if: (1) (a) I intend that we $\mathrm{J}$ and (b) you intend that we $\mathrm{J} ;(2)$ I intend that we $\mathrm{J}$ in accordance with and because of (1) (a), (1) (b), and meshing sub-plans of (1) (a), (1) (b); and you intend likewise. (3): (1) and (2) are common knowledge between us." 27

Bratman proposes, then, that what our intention amounts to is a complex of, as he puts it, 'interlocking' singularist-intentions. Since initially formulating his account Bratman has been developing a more complex set of conditions (see Bratman, forthcoming). The fundamental condition remains condition (1), which posits personal intentions of you, on the one hand, and I, on the other, in favor of our J-ing. By now many other theorists working from a personal intentions perspective have offered accounts that differ in one way or another from Bratman's in its various versions. ${ }^{28}$

Starting with observations on the way people think and talk about shared intention in everyday life, my own inquiries have led in a different direction. As I explain, they have suggested to me three central criteria of adequacy for an account of shared intention. In what follows I spend most time on the criterion I introduce first. This very clearly rules out accounts of shared intention in terms of personal intentions. The other criteria also throw doubt on such accounts. I then sketch the account I have developed and explain how it meets the criteria. Finally I note some important aspects of its relationship to personal intentions accounts with special reference to that of Michael Bratman.

\section{The Disjunction Criterion}

The criterion I first introduce concerns the relationship of a given shared intention to a certain kind of personal intention. Recall that a personal intention is understood here as an intention of an individual human being that is expressible by him in a sentence of the form 'I intend [...]'. Before proceeding to the criterion I say something more about personal intentions generally.

\footnotetext{
26 Michael Bratman is a leading contemporary figure in this area. See Bratman 1987. His interest in shared intention was an offshoot of this earlier work. The same goes for John Searle. Raimo Tuomela also previously worked on action theory.

27 This derives from the recapitulation in Bratman 1999, 131.

28 Other appeals to personal intentions in related contexts include MacMahon 2005; Miller 2005; Kutz 2000a; 2000b; Roth 2004 and Tuomela/Miller 1988. I discuss Kutz's approach in Gilbert 2002b.
} 
I take it that one who makes a personal decision to do such-and-such in the future, and has not subsequently changed his mind, thereby has a personal intention to do such-and-such. He may be said, also, to plan to do it.

One is, indeed, in a position to change one's mind or, in more technical parlance, to rescind one's personal decision. Such rescission may not be appropriate in a given circumstance, but one is in a position to bring it about unilaterally, at will. Moreover, no one else is in this position. I can persuade you to change your mind, but I cannot directly change it. I do not mean here to explore why this is so. I take it to be so, intuitively, and to be an important aspect of decisions and those personal intentions associated with them.

Some future-directed intentions may not be associated with decisions. Perhaps one just finds oneself with the intention. In that case, too, one is in a position to change one's mind, and no one else can do it for one.

I need next to introduce one more technical phrase. Suppose that two people share an intention to go shopping tomorrow. Some theorists may think that, as a conceptual matter, each must then personally intend to contribute as best he can to their going shopping tomorrow. None are likely to deny that each may so personally intend. Setting that issue aside, if one party does so personally intend, I shall say that he has a (personal) contributory intention with respect to this personal intention.

I shall argue that, as a conceptual matter, when two or more people share an intention, none of them need to have a contributory intention. The point is not that generally speaking when there is a shared intention there are no such intentions. The point is, rather, that it is in principle possible correctly to ascribe a shared intention to the parties when one or more of them lack contributory intentions.

This point does need arguing, and a pertinent mode of argumentation is appeal to one or more examples. ${ }^{29}$ So consider the following imagined retrospective report by one of the parties to a past shared intention. It should be considered, of course, without assuming the correctness of any particular account of what a shared intention is.

The parties are Ned and Olive, and Olive is speaking: 'Our plan was to hike to the top of the hill. We arrived at the hill and started up. As he told me later, Ned realized early on that it would be too much for him to go all the way to the top, and decided that he would only go half way. Though he no longer had any intention of hiking to the top of the hill, he had as yet said nothing about this to me, thinking it best to wait until we were at least half way up before doing so. Before then we encountered Pam, who asked me how far we intended to go. I said that our intention was to hike to the top of the hill, as indeed it was.'

I do not find that Olive's report is inconsistent. If it is not, one can conclude that people may share an intention though at least one of them lacks personal cotributory intentions. I say 'at least' one of them. In fact it seems that none of the parties need have such personal intentions. Thus I would not take Olive now to involve herself in an inconsistency if she went on: 'As it happens, when we met Pam, I was in the same position as Ned: I'd also decided that I would not

29 See also Gilbert 1997. The discussion that follows here is more extensive. 
go all the way to the top of the hill, though I hadn't yet broached the subject with him.'

There is a general argument to the conclusion that I have drawn from Olive's story in its longer version. This argument refers to the relationship between shared intention and agreements.

Michael Bratman has objected to the claim that an agreement brings a shared intention into being (Bratman 1993, 111n31). He says that it "[...] seems to me wrong, since binding agreements do not guarantee intentions on the part of the individual agents to act accordingly". I take him to be referring here to personal intentions. I am not quite sure what he has in mind by a 'binding' agreement as opposed to an agreement, period, but I shall assume for the sake of argument that he means an agreement on what is to be done by the parties, as opposed to an agreement on terms, and shall refer in what follows simply to agreements. ${ }^{30}$ To be sure, agreements do not guarantee personal intentions of the kind in question.

Consider the following version of Olive's story: 'Ned and I agreed to hike to the top of the hill that afternoon. Given our plan, we set off after lunch for the hill, and began to hike up it. As he told me later [...]' The story goes on as before.

One can imagine, indeed, that even while agreeing to hike to the top of the hill, thus intentionally cementing their shared intention, Ned was planning not to go to the top of the hill. Perhaps Olive was in the same position. That does not mean that he and Olive failed to enter a binding agreement to hike to the top of the hill.

In such a case one might want to say that neither party entered the agreement sincerely, meaning by this that neither intended to conform to it even while it was being made. By hypothesis, however, and compatibly with this, each did intend to make an agreement with the other. And we may assume that neither would ever think of denying that an agreement was made.

One can and, I think, should turn on its head Bratman's argument from the point that agreements do not guarantee contributory personal intentions. According to a firm pre-theoretical judgment, an agreement to do something immediately gives rise to a shared intention. Given Bratman's point, it follows that the parties to a shared intention need not have contributory personal intentionseither at the time the shared intention was formed or at any time prior to its satisfaction.

To endorse this argument is of course not morally or otherwise to endorse the creation with others of shared intentions for which one lacks the contributory personal intentions, or even guesses that one will lack them. Nor is it to approve one's deciding not to conform to a standing shared intention. All else being equal, these things should doubtless be discouraged. My point is only that these things are possible. That is what matters when the issue is the nature of shared intention.

As can easily be seen, my arguments here apply not only to personal contributory intentions, but also to the specific form of personal intention that figures in

\footnotetext{
30 An example of an agreement on terms: we agree that if you work for me, the pay will be $\$ 20$ per hour.
} 
Bratman's account of shared intention, a personal intention that we J. It applies more generally to any personal intentions explicitly geared to the satisfaction of a given shared intention. I shall refer to such intentions as correlative personal intentions.

In light of the foregoing I propose the following criterion of adequacy:

an adequate account of shared intention is such that it is not necessarily the case that for every shared intention, on that account, there be correlative personal intentions of the individual parties.

I shall call this the disjunction criterion. In what follows I shall assume its correctness. Recall that I am here construing an adequate account of shared intention as one that provides individually necessary and jointly sufficient conditions on shared intention. The account I have developed, to be described shortly, does not entail that there are correlative personal intentions whenever there is a shared intention. Nor, quite properly, does it rule them out.

Accounts in terms of correlative personal intentions of one or another kind clearly fail to satisfy the disjunction criterion. They fail, therefore, to provide a set of conditions that are individually necessary and jointly sufficient for shared intention.

A set of conditions or structure whose core was a set of correlative personal intentions could yet be sufficient for shared intention. In speaking of a structure whose core is a set of such personal intentions I mean to rule out a structure with correlative personal intentions within it, such that it is indeed sufficient for shared intention but only by virtue of those parts of the structure not involving the correlative personal intentions.

The interesting question is whether a structure of correlative personal intentions, more or less, is ever sufficient for shared intention. The qualifier 'more or less' here is intended to cover such further features as the parties' knowledge of each other's personal intentions, the mutual reinforcing influence of this knowledge, and so on. I shall henceforth construe the personal intentions perspective in these terms.

If some structure of correlative personal intentions is indeed sufficient for shared intention, then given the disjunction criterion, the hope of giving a set of individually necessary and jointly sufficient conditions on shared intention will have to be abandoned. This may not seem to be too large a cost. Remember, however, that I am focusing here on a particular class of shared intentions, those for which one might think that a personal intentions account would be most plausible: the class of shared intentions of particular individuals without pertinent authority relations. This is the class on which Michael Bratman, for instance, focuses. It is not implausible to expect that what is in my sense an adequate account of these, at least, can be found

I grant that in spite of this it is of interest to consider whether we can find a structure of correlative personal intentions that is sufficient for shared intention in these or other cases. That one cannot is suggested by two further criteria of adequacy for an account of shared intention. 


\section{The Concurrence Criterion}

I shall call the two further criteria of adequacy to which I now turn 'the concurrence criterion' and 'the obligation criterion' (see also Gilbert 1997). The naturalness of the following story can be used in support of both.

Queenie and Rom intend to do some shopping in a nearby town. In order to get there in time they must walk some miles along a dusty road at a certain pace. They are now half way along the road. Queenie's pace begins to slow. In a tone of mild rebuke Rom says 'Can you hurry up a bit? We won't be able to get any shopping done at this rate!' Queenie says 'Sorry!' and moves more quickly for a while. Later she stops and for some reason announces: 'That's it! I'm not going any further! ${ }^{31}$ Rom is likely to be taken aback. Whatever he says, his thoughts may well run along these lines: 'You can't just decide to stop here, not just like that!' Sotto voce or not, he might add by way of explanation: 'We're on our way to the shops!' Had Queenie said something like 'Do you mind if I stop here?' - seeking his concurrence in her stopping - his reaction would have been different. Then she would not have been 'simply deciding' to stop.

The likelihood of such thoughts and reactions in the presence of a shared intention suggests, for one, something like the following criterion of adequacy for an account of shared intention.

According to the concurrence criterion, to be further explained shortly:

an adequate account of shared intention will entail that, absent special background understandings, the concurrence of all parties is required in order that a given shared intention be changed or rescinded, or that a given party be released from participating in it.

I take it as read that the account should be such that the parties to the shared intention will understand that their concurrence is required as stated, and that, in addition, they will understand that this is a matter of what shared intention is. That the shared intention itself is understood to ground the need for concurrence is indicated by the naturalness of Rom's explanation of his 'You can't just decide!' with 'We're on our way to the shops!' This presents itself, indeed, as a complete explanation of the need for concurrence.

The qualifier 'absent special background understandings' is important, and should also be taken as read in what follows. It allows that prior agreements such as the following are possible. Queenie is not sure she wants to walk all the way into town that afternoon, so before she and Rom set out on their shopping expedition she gets him to agree in advance that if at any time she feels like stopping, she is free to do so. Against this background, Rom would not react as in the original story. For now, given their agreement, Queenie can just decide, 'just like that'. The qualification is crucial: Rom can be considered to have concurred in advance with any proposal from Queenie that she not go all the way into town. ${ }^{32}$

\footnotetext{
31 Perhaps, as a follower of ethnomethodologist Harold Garfinkel, she is bent on teasing out reactions to behavior she believes is 'out of line'.

32 A reader may be reminded of the duet-singers in Bratman 1993, to whom I recur later.
} 
The concurrence criterion in effect spells out the most plausible interpretation of Rom's 'You can't just decide!' He means that Queenie is not in a position unilaterally to decide to stop where she does - not without coming up against their shared intention. What is required to render her action faultless in the relevant respect is Rom's concurrence with her stopping.

One can of course make a personal decision not to act in accordance with a shared intention; this is what Queenie does in the initial story. It is also what Ned does in the story of his shared intention with Olive to hike to the top of the hill. What neither Queenie nor Ned is in a position unilaterally to do by virtue of his or her own decision, in and of itself, is change, rescind, or release themselves from participation in the pertinent shared intention in such a way as to make faultless their acting contrary to it.

I shall now assume that the concurrence criterion must indeed be satisfied by an adequate account of shared intention. ${ }^{33}$ Given that criterion, there is another significant problem for the personal intentions perspective.

As discussed earlier, one is a position unilaterally to rescind one's personal intentions. One is also in a position unilaterally to alter them with respect to some detail. One can 'just decide' to do so, and it is done. Thus, though one might beg someone else not to change his mind, point out some undesired consequence of his doing so, malign him for doing so, and the like, it is not true as a matter of what a personal intention is that he is not in a position to do it without one's concurrence.

This criterion has, it seems, a sharper edge than the disjunction criterion. According to that criterion, there need be no correlative personal intentions given a shared intention. Though this means that there cannot be a correlative personal intentions account of shared intention that is adequate in the sense at issue here, the criterion leaves open the possibility that a structure of personal intentions may be sufficient for shared intention.

Given the concurrence criterion it is hard to see that such a structure can indeed be sufficient for shared intention. If a shared intention is such that one cannot unilaterally release oneself from participation in it by a simple change of mind, there must be something other than a structure of personal intentions at the core of any shared intention. For given any personal intention, the person with that intention is in a position to rescind it, and hence in effect demolish the shared intention itself, simply by changing his mind.

\section{The Obligation Criterion}

As I explain, a further criterion of adequacy for an account of shared intention is suggested by the following part of the story of Rom and Queenie's shopping expedition: when Queenie starts slowing down, Rom says, in a tone of mild

Bratman's example is pertinent to both criteria though not, I think, adversely. For an extended discussion of background understandings of the kind in question here, see Gilbert 2006, ch. 6.

33 There is a much longer pertinent discussion of a similar concurrence condition with respect to joint activity (as opposed to shared intention) in Gilbert 2006, ch. 7; see also Gilbert 1997. 
rebuke, 'Can you hurry up a bit? We won't be able to get any shopping done at this rate!' In other words, she is acting in such a way as to make it hard for them to fulfill their shared intention.

In speaking as he does Rom both mildly rebukes Queenie for slowing down, and implicitly demands that she hurry. Her 'Sorry!' presupposes his standing to make this demand and to rebuke her as he does.

This suggests something like the following obligation criterion:

an adequate account of shared intention will entail that each party to a shared intention is obligated to each to act as appropriate to the shared intention in conjunction with the rest.

In parallel with my assumption regarding the concurrence criterion, I take it as read here that the account should be such that the parties to the shared intention will understand that they have the stated obligations, and that they understand that this is so as a matter of what a shared intention is. Thus in explaining the rebuke and his demand that are the focus here - as in explaining his 'You can't just decide to stop!' - Rom might simply have said 'We're on our way to the shops!'

I take the obligation criterion to imply that each has an obligation to form, as and when necessary, personal intentions that mesh appropriately with those of the other party or parties. ${ }^{34}$ One can, of course, fail to satisfy these obligations: their existence is not disproved by such failure.

It is important to emphasize that the obligation criterion, as just set out, concerns obligations of a particular type. Thus in my formulation of the criterion each party is said to be obligated to the other parties to do something. I shall refer to obligations of this type as directed obligations, using an established phrase that is appropriate here. Before I say why the criterion is couched in these terms, it will be helpful to say more about directed obligations as I shall construe them here.

Rights theorists commonly use the language of directed obligation: one person's right against a second person to an action of the second person is said to be equivalent to the second person's obligation to the right-holder to perform the action. The word 'duty' is often substituted for 'obligation' in the formulation given here. ${ }^{35}$ Rights of the kind in question are generally known as claim-rights or claims. ${ }^{36}$

The obligation criterion, indeed, could just as well have been labeled the rights criterion, as long as that is understood to refer to rights that are the equivalent of directed duties, as opposed to some other kind of right, such as a liberty-right. It might be thought that in order to understand better the nature

\footnotetext{
34 This point recalls the 'meshing sub-plans' Bratman 1993 invokes, and emphasizes, in his account of shared intention. This is clearly pertinent to the relations between our accounts to which I turn later in the text.

35 Hart 1955 explicitly prefers 'obligation'.

36 The classic reference here is Hohfeld 1919/1964. That species of rights Hohfeld calls claims (rights against persons to actions of those persons) are said to have, as their 'correlative and equivalent', duties towards the right-holder. I shall not here speculate on why Hohfeld chose the label he did, something he did not make explicit.
} 
of directed duties one can simply reach into the theory of claim-rights for an answer. There is great controversy among rights theorists, however, as to what a claim-right amounts to. The same goes, not surprisingly, for the nature of directed obligations.

As to the latter, as far as the theory of shared intention goes, I would argue that the interpretation we need is in terms of owing, an interpretation given by two distinguished rights theorists, H. L. A. Hart and Joel Feinberg. In this construal, the parties owe each other action appropriate to the shared intention (Hart 1955; Feinberg 1970). To say that, however, is not to conclude discussion.

People use the term 'owe' in different ways, not always in a way that is appropriate here. For instance, one may say 'I owe him a favor' without meaning that he has a right to a favor from you. To say that for one person to owe another an action, in the present context, is for that other to have a right against him to the action in question is, of course, true. It is only helpful in the present context if it is clear what such a right amounts to.

I find an important clue in this. Feinberg refers at one point to a right-holder's demanding what he has a right to as his (Feinberg 1970). This implies that if I owe someone a certain action, in the sense of 'owe' in question here, he already in some intuitive sense owns that action. On hearing this one may wonder if it can be correct. In what sense can one own the future action of another person? I believe that something can be made of it, as I explain later. For now I explain how some pertinent, and important intuitive ideas in addition to those of owing and claim-rights fit together with the idea of one's owning, in some intuitive sense, another's action.

Feinberg refers to a right-holder's demanding something as his. I take this to offer us a plausible way to amplify the nature of a demand,or, if you like, a demand that is something more than a seriously intended imperative. Anyone is in a position to address such an imperative to anyone else. Indeed, if one issues such an imperative while threatening some undesired consequence if its addressee does not conform to it - for example, if one is brandishing a gun while saying 'Hand over your money!'- one is likely to be successful in obtaining such conformity. For a demand in the sense in question here one needs a special standing. The same goes for the issuing of a rebuke, which might be thought of as a retrospective demand. ${ }^{37}$

The idea about demanding that I take from what Feinberg says is this: to be in a position to demand something from someone is for it already to be in some intuitive sense one's own. That is because demanding in the relevant sense is demanding as one's own. This, Feinberg implies, is something any claim-right holder can do with respect to an action to which he has a right.

This suggests that there is an important and closely linked family of concepts here: the concept of a right to some future action of the right's addressee, one's current ownership, in some intuitive sense, of that action, one's being owed that action by the right's addressee prior to his performing it, one's being in a position to demand it of him prior to its performance, and one's being in a position to

37 On concepts that can only be applied to one with a special standing see also Gilbert 2006, ch. 1 . 
rebuke him if he has failed to perform it at the appropriate time. The linkage can be displayed as follows: one who has a right to someone's future action already owns that action in some intuitive sense of 'own'. Until the action is performed he is owed that action by the person concerned, thus being in a position to demand it of him prior to its being performed and to rebuke him if it is not performed. If it is performed, one might say that it has finally come into the possession of the right-holder, in the only way that it can.

This all suggests a way of interpreting the obligation criterion that fits the observable facts about shared intention and offers a plausible interpretation of them. Consider again the case of Rom and Queenie. Rom both rebukes Queenie (albeit mildly) for going too slowly for the satisfaction of their shared intention, and demands that she speed up if she can. Queenie implicitly accepts his standing to issue such rebukes and demands when she says 'Sorry!' In so doing she acknowledges, in effect, that at the time he spoke Rom had a right against her to actions appropriate to the shared intention; and that she owed him such actions, which he already in some sense owned. In other terms, she has the corresponding directed obligation to perform such actions. Intuitively the same goes, with appropriate changes, for the parties to any shared intention.

One who accepts the obligation criterion so interpreted - as I shall in what follows - could also posit as a criterion of adequacy a 'standing to demand' criterion and a correlative 'standing to rebuke' criterion. This is redundant, strictly speaking, once one has clarified the nature of the obligation at issue in the way just indicated. If you owe me your action in the sense that implies that I already in some sense own it, I am in a position to demand that action as mine and to rebuke you when you fail to perform it.

Standing, incidentally, must be sharply distinguished from justification. One may have the standing to demand something of someone, yet not be justified in doing so, in the circumstances. Thus were Queenie so sensitive to criticism that she would suffer a grave physical crisis if rebuked, in most circumstances it would be wrong to rebuke her even if one had the standing to do so.

So much, then, in explanation and justification of the obligation criterion. There are various ways in which it might be satisfied. An account of shared intention could list one or more other conditions from which the pertinent obligations of the parties did not follow and then explicitly posit, in addition, the existence of such obligations. That would be unsatisfactory because it would not explain the ground of the obligations.

More desirable would be an account such that the conditions it explicitly posits - which do not explicitly stipulate the necessary obligations of the parties - are such that it follows from them that the parties have these obligations. This way, the source of the obligation would be completely clear. It would also fit well with the observation made earlier that one who calls another on his inappropriate action may well justify his intervention by reference simply to the shared intention. This suggests that the existence of the necessary obligations - providing the standing to demand and rebuke - is understood to be grounded in other conditions the shared intention satisfies. Thus no reference 
to further, 'external' factors such as expectations or reliance generated by the shared intention, or to side or background promises or agreements, is needed.

The obligation criterion, like the concurrence criterion, argues against the sufficiency of an account of shared intention in terms of correlative personal intentions. For, though my personal intention constrains my behavior, it does not in and of itself entail that I owe you the intended action.

Michael Bratman has allowed that when there is a shared intention in his sense, there are not necessarily any mutual obligations of the parties. At the same time he has in various ways argued, in effect, against the obligation criterion. I briefly review and respond to three of those arguments here. ${ }^{38}$

One argument involves the example of two duet-singers who "each value their duet-singing but nevertheless have a clear understanding between them that neither is making any binding promise to or agreement with the other concerning their singing. Each publicly states that she reserves the right to change her mind." (Bratman 1993, 111) There are various ways of construing this example.

If we give the most natural reading to 'their duet-singing' we should allow that these singers do have an established shared intention. At the same time we can construe their 'clear understanding' as, in effect, a side-agreement to the effect that each may proceed as if they have no obligations to one another with respect to their duet-singing. The possibility of such a side-agreement does not force us to reject the obligation criterion. A similar point was made earlier in relation to the concurrence criterion (see also Gilbert 2000, 35n36).

Another argument alludes to a case involving coercion. Here is the version of it that best fits the present juncture in my own discussion. I tell you that unless you share with me an intention to sing a duet, I will blow up your house. This threat leads you sincerely to act in such a way as to establish that now we have the shared intention in question. Of this scenario Bratman says "it seems to me that in this case I have no entitlement to your playing your part" (Bratman 1999, 132-133).

I agree with Bratman that a shared intention can be established in these circumstances. I suggest, however, that once the shared intention has been established in the way described, you may well refrain from acting in a way inconsistent with it because you understand that, fortunately or not, you now owe me actions consistent with that shared intention. Perhaps there are considerations on the other side. And you may judge that all things considered it is rationally permissible not to fulfill your obligation to me. You are likely still to have it in view, and to recognize my standing to rebuke you for failing to fulfill it.

It is quite possible - likely, in fact - that Bratman is thinking of entitlements of a specific kind, and that the parties to a shared intention have rights against each other of another kind. Then his judgment on this case could be correct in its own terms, but it would not tell the whole story about shared intention and obligation. ${ }^{39}$

\footnotetext{
38 In doing so I focus on material that was published prior to the completion of this paper.

39 I discuss the related case of coerced agreements at length in Gilbert 1996, ch. 12. See also Gilbert 2006, ch. 10.
} 
Another argument alludes to shared intentions to do something bad. Bratman assumes that these cannot involve obligations to act in favor of the shared intention. ${ }^{40}$ Yet those who share intentions to do bad things may well think otherwise; and, as in the previous case, it is possible that Bratman's negative conclusion is valid only for a kind of obligation other than that involved in shared intention - which is what I believe is the case. I return to this issue later in the paper.

Though inclined to reject the obligation criterion, Bratman believes that the parties to a shared intention according to his account often have obligations to one another to act in favor of the shared intention. This could be due to prior agreements or promises. Or it may be due to factors downstream from the shared intention - perhaps not very far downstream - which trigger a moral principle such as the one argued by Thomas Scanlon to explain the moral wrong involved in promise-breaking, but not that alone, a principle he dubs "Principle F". ${ }^{41}$

All this may well be true. Allowing for the sake of argument that it is, it cannot be the whole story of the obligations associated with shared intention.

As Bratman would agree, shared intentions can arise without a background agreement or promise. Yet, as argued earlier, a shared intention is sufficient in and of itself for the obligations in question. What of downstream factors such as expectations and reliance, coupled with Scanlon's Principle F, or something like it? Since these are indeed downstream factors they cannot accommodate the intuition that obligations inhere in the shared intention. There is, in any case another problem with this move.

As I have argued elsewhere, the application of a principle such as Scanlon's Principle $\mathrm{F}$ to a given party does not show that the other party has a claim-right against him, along with the standing to demand as his what he has a right to. Rather, it shows that the first party is morally required to act in favor of the shared intention, subject perhaps to certain conditions. ${ }^{42}$

In sum, though Bratman and other personal intentions theorists may be able to argue for the existence of various obligations that are in the offing when there is a shared intention, they may not be able to account for the directed obligations that, intuitively, inhere in the shared intention itself.

\footnotetext{
40 See Bratman 1999, 132n6. Others have had this reaction in related contexts. For discussion of the related case of immoral agreements (along with case of coerced agreements) see Gilbert 2006, ch. 10.

41 ' $\mathrm{F}$ ' stands for 'fidelity'. Since the details of this complex principle are not of central importance here I do not quote it. See e.g. Scanlon 1998.

${ }^{42} \mathrm{I}$ argue at length that Principle F, in particular, does not suffice to explain the rights of promisees, in particular, in Gilbert 2004. I also raise doubts there about the sufficiency for this purpose of moral principles more generally. In the case of an application of Principle F specifically, the condition that needs to hold is that the second party does not say it is fine with him that the first party not act in favor of the shared intention. See Gilbert 2004 on unhelpfulness of this clause in explaining the rights of a promisee.
} 


\section{The Plural Subject Account of Shared Intention}

As I shall explain, the account I have been developing respects the disjunction, concurrence and obligation criteria. I first present the account without explanation. The ensuing discussion will explain the technical terms involved and clarify some further aspects of the account.

In its most general form the account runs as follows:

Members of some population $\mathrm{P}$ share an intention to do $\mathrm{A}$ if and only if they are jointly committed to intend as a body to do A.

For two-person cases of the type on which I have been focusing in this paper it would run, more specifically, thus:

Persons $\mathrm{X}$ and $\mathrm{Y}$ share an intention to do $\mathrm{A}$ if and only if $\mathrm{X}$ and $\mathrm{Y}$ are jointly committed to intend as a body to do A.

Both formulations include some technical terms that require explanation. In particular I must explain what it is for people to be jointly committed in some way and what it is to intend as a body to do A. I start with joint commitment.

The relevant concept of commitment can usefully be introduced, albeit roughly and briefly, by reference to personal intentions and decisions, since people are committed by them in the appropriate sense of commitment. The cases of intention and decision are somewhat different. As to decisions, if I have decided at $\mathrm{t}$ to do $\mathrm{A}$ at time $t+1$, and have not subsequently rescinded my decision, then I have sufficient reason to do $\mathrm{A}$ at $t+1$. As to intentions, if at time $\mathrm{t} \mathrm{I}$ intend to do $\mathrm{A}$ at $t+1$, and my intention has persisted to $t+1$, then $\mathrm{I}$ have sufficient to do $\mathrm{A}$ at $t+1 .{ }^{43}$

The central point for present purposes is that given either a standing, unrescinded decision or an intention, the person in question has sufficient reason to act in a particular way even without this having been the case prior to the formation of the intention or decision. In saying that one has sufficient reason to act in some way I mean that, if all else is equal, one ought so to act. The "ought" here is a matter of what might be referred to as rational requirement, such that one is not being appropriately responsive to the considerations that bear on the case if one fails to act as one ought. ${ }^{44}$

Sometimes, I take it, all else is not equal. That is, all things considered, I ought not to do A, in spite of my decision or intention to do it. Perhaps doing $\mathrm{A}$ is imprudent or immoral. ${ }^{45}$ Then, all things considered, I ought not to do A.

\footnotetext{
43 I have elsewhere summarized this point by saying that decisions but not intentions have trans-temporal reach. Clearly the notion of trans-temporal reach is distinct from the notion of relating to the future. See Gilbert 2006, ch. 7 , where there is a longer discussion of decisions versus intentions in the context of a discussion of joint commitment. On 'having sufficient reason' see the text following.

${ }^{44}$ For concordant discussion see Verbeek 2007. For present purposes I shall not attempt to argue the point.

45 In the case of decision, even if all else is not equal, so that one ought not to act in accord with one's decision all things considered, I take it that something is amiss if one fails to change
} 
I do not mean to imply that either decisions or intentions are "reasons" in a particular sense of "reason" on which many contemporary philosophers have focused. Such reasons are, we might say, considerations for and against a particular action that would appropriately be weighed prior to making a decision whether or not to perform it.

Personal decisions and intentions create commitments of a kind I shall call personal commitments. For present purposes the key salient feature of such commitments is that the one who personally formed or made the corresponding personal decision or intention is in a position unilaterally to expunge it as a matter of personal choice. ${ }^{46}$

A joint commitment is not a concatenation of personal commitments. Thus it is not formed by virtue of the formation of a personal commitment by each of the parties. In particular, as I have emphasized elsewhere, its formation is not achieved by the expression of a conditional personal commitment which is met by a clinching expression from the other party or parties. ${ }^{47}$

How, then, is a joint commitment created? In the basic case, on which I focus here, each of two or more people must openly express his personal readiness jointly with the others to commit them all in a certain way. ${ }^{48}$ I mean to imply here that each is indeed personally ready for this, and that he expresses this readiness. ${ }^{49}$ Once the concordant expressions of all have occurred and are common knowledge between the parties, the joint commitment is in place.

I make some further points regarding the creation of a joint commitment shortly. Before that I say something to clarify the idea that those who share an intention are jointly committed to intend as a body to do something.

I should say at the outset that there can be joint commitments not only to intend as a body to do something but also to believe as a body that such-and such, to accept, as a body, a certain rule, and so on. The content of every joint commitment can be represented in a similar way. That is, whatever its content, a joint commitment can be represented as a joint commitment to 'do' something as a body, where "doing" is understood in a broad sense so as to include intending, believing, accepting, and so on.

For the sake of a label, I say that those who are jointly committed in some way constitute a 'plural subject'. ${ }^{50}$ Those who are jointly committed in one way may

one's mind yet acts contrary to the decision. This could happen if one simply forgets one's decision and goes ahead and acts contrary to it-without explicitly changing one's mind. I shall not pursue this aspect of the matter here, though I take it to be significant.

46 Perhaps this is true also of an individual's we-intention as Searle 1990 understands it-a different type of singularist-intention. To my knowledge Searle has not addressed this issue; I shall not attempt to pursue it here.

47 Some tentative formulations in Gilbert 1989 may have led to misunderstanding in this respect; though see e.g. 282, which attempts to forestall such misunderstandings. The position involving conditional personal commitments criticized in Roth 2004, then, is not mine. See Gilbert 2003 for more discussion on this point.

48 Non-basic cases involve authorities whose status derives from a basic joint commitment. See Gilbert 2006, ch. 7.

49 In Gilbert 1989, ch. 4 I argue for an 'expressed' condition as well as an 'expression' condition.

50 I first used 'plural subject' as a technical term in Gilbert 1989. 
also be so committed in one or more other ways. In that case one can say that they constitute the plural subject of an intention, a belief, and so on, depending on the case. Given the meaning of my technical phrase 'plural subject' I dub the account of shared intention I am discussing the plural subject account of shared intention.

There is doubtless more than one way further to articulate the idea of a joint commitment to intend as a body to do something. The way that I have tended to adopt keeps the word 'body' in play. Thus one might put things roughly as follows: the parties are jointly committed as far as possible to emulate, by virtue of the actions of each, with respect to its intending, a single body that intends to do the thing in question.

In this formulation speech and deliberate inaction are understood to be included under 'actions'. Taking as read the qualifiers 'as far as possible', 'by virtue of their several actions' and 'with respect to its intending' we have something a little more pithy: the parties are jointly committed to emulate a single body with a certain intention. I shall generally use this shorter formulation in what follows.

What is a 'single body' as I construe the phrase? I take it that whereas a single human being constitutes a single body, in the sense I have in mind, a plurality of human individuals does not and cannot constitute such a body. At least to some extent, however, such a plurality can emulate such a body - one with a plurality not only of limbs, eyes, and ears, but also of noses and mouths. ${ }^{51}$

As I have said in a number of places, I am not wedded to the use of the term 'body' in my account of the content of a joint commitment or in the specific case of shared intention. One might substitute in the previous formulation the term 'person', for instance, or 'agent'. Another possibility that eschews any talk of emulation is to say something along the following lines: a joint commitment to intend as a body to do something is a joint commitment as far as possible to produce, by virtue of the actions of each, a single instance of intending to do that thing.

As to what precisely is intended, we need a felicitous way to deal with the fact that some of the things we may share an intention to do are designed for two or more participants - things such as playing a duet or a game of basketball or tennis - and some are not so designed. For instance, we may intend to prepare a meal, solve a problem and go for a walk.

Consider a case of the latter kind. Suppose that Sally and Tim share an intention to go for a walk. Understanding what it is to intend as a body along one of the lines suggested, we might articulate their situation as a whole roughly as follows: Sally and Tim are jointly committed to intend as a body to produce, by virtue of the actions of each, a single instance of going for a walk with the two of them as the participants in that walk.

51 To the extent that the parties can emulate such a body, and only to that extent, they can constitute one. In previous writings I have tended to write of the parties being committed to 'constitute as far as possible a single body that does such-and-such'. I think an appeal to emulation is more helpful here, though the other characterization can stand if understood as just indicated. 
One can expect this spare and basic idea to be filled out in concrete situations by background social conventions or explicit agreements between the parties as to how a walk for two is to proceed. Thus the social conventions to which I am a party dictate that when we go for a walk, we walk alongside each other, unless the terrain requires us to do otherwise. Other such conventions might require the parties to walk in single file, or for parties of one social class or gender to work ahead of those from another social class or gender, and so on.

I turn now to a case of the other kind: Sally and Tim now intend to play a game of tennis. This can be understood in a parallel way, roughly as follows: Sally and Tim are jointly committed to intend as a body to produce, by virtue of the actions of each, a single instance of a tennis game with the two of them as participants in that game.

I return now to the question of how a joint commitment is created. As said, it is necessary and sufficient for the creation of a joint commitment that each party express his personal readiness jointly to commit them all in a certain way, in conditions of common knowledge. The necessary expressions of readiness can take various forms.

Some may involve a verbal agreement as in: 'Shall we go to London together?' 'Okay!' I have argued elsewhere for an understanding of everyday agreements generally in terms of joint commitment. ${ }^{52}$ I propose more specifically that such an agreement is a joint decision, where such a decision is made by an explicit process such as that in the example, creating a joint commitment of the parties to endorse as a body a particular plan of action.

A less explicit process is also possible. ${ }^{53}$ This may or may not be considerably extended in time. Then, what emerges will not involve a joint commitment to endorse as a body a certain explicitly formulated decision, but will simply be a jointly commitment to intend as a body to do something.

A practically important aspect of any joint commitment is this. Like a personal commitment it can only be rescinded by the 'one' who created it: in this case, absent special background understandings, that 'one' comprises those who jointly committed themselves by their concordant expressions. Together they constitute the creator of the commitment; the 'one' who imposed the relevant normative constraint on each of the parties.

With respect to the ending of a joint commitment arrived at without an agreement it may be more apt to speak of something other than 'rescission', which conjures another focused, dated process, with respect to its demise (see Gilbert 2006, 141-143). In order not to complicate matters I shall continue to write of 'rescission' in what follows.

I have argued elsewhere that the concept of joint commitment just sketched lies at the foundation of many central everyday concepts including those of a social rule, an interpersonal agreement, a group's language and a group's belief. ${ }^{54}$

\footnotetext{
52 My argument is summarized in Gilbert 2006, ch. 10. For more detail see Gilbert 1996, ch. 13.

53 As in case described earlier of students Jake and Kristen. For further examples in the context of a discussion of joint commitment generally see, e.g., Gilbert 2006, ch. 7 .

${ }^{54}$ In Gilbert 1989 with amplifications and further points made elsewhere. See Gilbert 1997 for a summary of the framework of analysis that has evolved therefrom.
} 
Its invocation as part of an account of shared intention, then, is by no means ad hoc. On the contrary, one reason for my initially proposing a plural subject account of shared intention was my prior recognition of the plausibility of such an account for other central social phenomena. Most of these accounts were argued for independently of the others.

\section{Some Questions about the Account}

Before turning to the relationship of the plural subject account of shared intention to the criteria of adequacy specified earlier, I address some questions that might be raised in response to what I have said so far.

Reflecting on the formulation in which one is jointly committed to intend as a body to do a certain thing, one might ask: do those who are jointly committed in some way thereby constitute a body in some intuitive sense of the word? In my technical terminology, is a plural subject itself a body of some kind? If so, is that a problem for my account of shared intention ${ }^{55}$

Suppose, as I think is plausible, that that any plural subject, in my sense, is indeed a kind of body. We might call the kind of body in question a collective body, or collective, understanding this to be a body that somehow comprises a number of single bodies in the sense invoked in the previous section, or a number of persons. ${ }^{56} \mathrm{My}$ proposal - in one formulation - is that a shared intention is a joint commitment to intend as a body to do something, where a 'body' here is understood to be a non-collective body.

Suppose then that certain persons constitute, by virtue of their joint commitment, a collective body that intends to do something. That clearly does not mean that their joint commitment requires no further action from them - that it is, in effect, pointless. On the contrary, each one must continue to act so that as far as possible they emulate, by virtue of their several actions, with respect to its intending, a single non-collective body with the intention in question.

I now briefly consider whether there is anything philosophically disreputable about the plural subject account of shared intention. Are there any sound ontological canons, for instance, that it transgresses? I think not.

Some people have, I think, read too much into my technical phrase 'plural subject'. For me, if and only if individuals $\mathrm{X}, \mathrm{Y}$ and any others are jointly committed in some way then - by my definition of 'plural subject' - they constitute a plural subject. If one finds joint commitment to be a philosophically acceptable notion, then there is nothing to quarrel with in my references to plural subjects, unless perhaps it is the label 'plural subject' as such.

If anything, that label is intended to suggest something for which I have argued. Namely, when they are not susceptible of a simple distributive reading, when they refer to a set of statements about what one might call 'singular

\footnotetext{
55 Thomas Smith raised these questions in conversation (personal communication, Helsinki, 2006).

56 I have long argued that a central everyday concept of 'social group' is more or less equivalent to the concept of a plural subject as I define that. See Gilbert 1989, ch. 4; also Gilbert $1990 ; 2006$, ch. 8. It is natural enough to think of a social group as a body of persons.
} 
subjects', each of which appropriately refers to himself as 'I', everyday references to what 'we' intend, and so on, are references to 'plural subjects' in my sense.

What, then, of joint commitment? Is it a philosophically acceptable notion? Whether or not one is committed in the sense appropriate to joint commitment is a matter of one's normative situation and its source. One is jointly committed with another person or persons if and only if one is committed, along with him or them, as a matter of the readiness of each together to commit them all in a particular way, which readiness has been mutually expressed in conditions of common knowledge.

I see in this description nothing philosophically disreputable. In particular, it fails to posit any metaphysically suspect group mind - the scary monster that is often invoked to in order to enhance the attraction of an account in terms of singularist-intentions, personal or otherwise. ${ }^{57}$ At the same time, the plural subject account implies that a shared intention is not constructed out of singularist-intentions. It is possible, then, to give an account of shared intention that is not constructed out of singularist-intentions, but which fails to posit any metaphysically suspect entities.

\section{Implications of the Account}

I now justify my claim that the plural subject account of shared intention meets the criteria of adequacy mentioned. As to the disjunction criterion, since a shared intention (according to the account) is a matter of joint commitment, it is logically possible for it to exist in the absence of correlative personal intentions of the participants. Thus the disjunction criterion is satisfied.

What of the concurrence criterion? What parties to a shared intention cannot do is alter or rescind the foundational joint commitment without the concurrence of the other parties, absent special background understandings. That latter point shows that the concurrence condition is satisfied.

I turn now to the obligation criterion, and argue briefly that this also is satisfied by the plural subject account. ${ }^{58}$ Recall what one needs to show according to this criterion: on the proposed account of shared intention the participants must owe one another future conforming actions, where that means that they already in some intuitive sense own these actions in advance of their performance. Each is therefore in a position to demand as his conforming actions of the others, and to rebuke the others for non-conforming actions. As indicated earlier one might be doubtful as to whether there is an intuitive sense in which one can own someone's future action. I propose that there is at least one such a sense, and that consideration of what happens when a joint commitment is made tells us what it is.

What I have in mind is roughly this. Crucially, in co-creating their joint commitment the parties together impose on each other a constraint such that,

\footnotetext{
57 Bratman 1993; Searle 1990, respectively.

58 Though I prefer the line of argument presented here, I have argued for the 'internally' obligating nature of joint commitment in other ways also. See Gilbert 2000, ch. 4.
} 
all else being equal, a given party will not act as he ought should he fail to respect $i t$. When this occurs one can say that the parties have together 'put their dibs' on the future conforming actions of each one, and that to that extent they have made them their own. Thus a given party is in a position to demand conformity or rebuke for non-conformity as co-owner of the action in question. Making things explicit, he might say 'Give me that, it's mine - qua one of us!'

I take it that when actions are owned in the intuitive sense now in question they are owed to their owners prior to performance. Thus the parties to a joint commitment owe one another conformity to it, qua parties to the commitment.

The foregoing line of argument for the obligating nature of a joint commitment is a matter of the authorship of the commitment and its constraining nature. The obligations of the parties are, one might say, purely internal to the joint commitment. These obligations exist irrespective of the content of the commitment in question: they exist whenever a joint commitment is made, whatever else is true. I now briefly explore some of the implications of this particular point.

On the face of it, it is possible for people jointly to commit one another to intend as a body to do something that considered in itself, apart from the commitment is morally impermissible - something that is, for short, an evil act. ${ }^{59}$ In saying this I do not mean that the action in question is seen by the parties as evil but that it is in fact evil. I shall assume for present purposes that such a joint commitment is indeed possible. ${ }^{60}$

Suppose, then, that Ulrich and Vance share an intention according to the plural subject account to do some evil thing. Each will then owe the other conformity to their intention, by virtue of the constitutive joint commitment. As each will understand, if the other wishes to call him on his non-conformity then he will have the standing to do so, since he is not being given what is owed him. In other terms, Vance and Ulrich are obligated to each other to conform to the constitutive joint commitment, though neither (I shall assume) ought to conform to it all things considered.

One may now be moved to say that there is a problem here for the plural subject account precisely because it implies that the parties to a shared intention to do evil are obligated in this way. That, one may say, cannot be the case. ${ }^{61}$ In saying this, one may well have in mind a type of obligation that is not here to the point. ${ }^{62}$ In particular, one may have in mind the obligations, duties, or requirements that accrue to those who fall under a moral principle such as Scanlon's principle F. Though I shall not attempt to argue this here, I would agree that it is impossible to have an obligation of this type to do evil. Call an obligation of this type a moral requirement. If one has a shared intention to do

\footnotetext{
59 I do not mean here to plump for some kind of deontological as opposed to consequentialist ethics. If you like read 'morally impermissible' as 'morally impermissible in normal circumstances', and read the rest of the discussion as assuming normal circumstances.

60 Any argument to the effect that it is not would most likely imply that a personal commitment to do what is in fact evil is impossible also. Both positions are on the face of it implausible.

61 Cf. Michael Bratman's reaction to the obligation criterion, discussed above.

62 For some discussion of so-called obligations as a genus and at least two significantly different species of so-called obligation see Gilbert 2006, chs. 2, 7, and elsewhere.
} 
$\mathrm{A}$, where $\mathrm{A}$ is an evil action in the sense at issue, then in my view it is not the case that one is morally required or obligated in that sense to conform to the constitutive joint commitment.

The directed obligations of joint commitment are another matter. As said above, if people can jointly commit to intend as a body to do some evil thing, it follows that they are obligated to one another to conform to that evil intention, whatever the circumstances. ${ }^{63}$ As I have put it elsewhere, the obligations that ensue from a joint commitment are not context-sensitive; moral requirements, on the other hand, are (Gilbert 1996, ch. 7; 2006, ch. 7).

\section{The Plural Subject Account and Personal Intentions}

What is the relationship of shared intention on the plural subject account to personal intentions of the parties to the shared intention? In briefly considering the question here I start by reviewing the core of Michael Bratman's personal intentions account of shared intention, whose initial formulation was detailed earlier.

According to Bratman, if we two share an intention to paint the house together, for instance, then each of us personally intends that we paint the house together, personally intends that we paint the house together by virtue of his own and the other's personal intention that we paint the house together, and personally intends that we do this on the basis of meshing personal sub-plans of each. ${ }^{64}$ Each is personally committed to act in accordance with his personal intention, in the sense of 'personal commitment' introduced earlier. A central aspect of a personal commitment in this sense is that one with such a commitment is in a position unilaterally to divest himself of it as a matter solely of his personal choice.

A first point to make in comparing this personal intentions approach with the plural subject account involves an important contrast. On the plural subject account the individual parties to a shared intention are necessarily committed in related ways. The commitments in question, however, are not personal commitments but rather what one might refer to as 'individual' commitments. ${ }^{65}$

\footnotetext{
63 I have applied these points to the question of commands to do evil in Gilbert (ms). For further discussion of joint commitments with immoral content see Gilbert 2006, ch. 10, which also discusses the related topic of joint commitments whose genesis involves coercion of one or more parties.

64 That Bratman has in mind personal sub-plans rather than shared sub-plans is indicated by such references as "the other's relevant sub-plans" (Bratman 1993, 105). Meshing sub-plans were a key ingredient in the account of shared intention in Bratman 1993; the larger set of conditions he has been developing include, e.g., the parties' personal willingness to help one another if needed to carry out the shared intention (e.g. Bratman 2008ms). Given Bratman's personal intentions perspective I take the addition just mentioned to be plausible insofar as the parties to a shared intention, like those who act together, tend both to expect and to manifest such helping behavior. See e.g. Gilbert 1989, ch. 4.

65 See Gilbert 1996, 11-13 for a detailed treatment of these 'individual' commitments. See also Gilbert 2003 and the text below.
} 
Thus suppose that Will and Xenia have a shared intention according to the plural subject account. If he proposes a shared sub-plan to her, and it is reasonable, there is already some onus on her to accept it, as a party to the fundamental joint commitment. ${ }^{66}$ In terms of commitment, she is already committed not capriciously to reject Will's proposal, an individual commitment deriving from the fundamental joint commitment of the two. The same goes for Will, of course, with relevant changes. I assume that something similar is true of those with the personal intentions at the core of Bratman's account, the derived commitments there being personal. There are important differences between the cases, however. I focus on one here.

In the case described, Xenia, for instance, cannot unilaterally revise or rescind the joint commitment from which her individual commitment derives, nor can she release herself from it. Thus her being subject to the derived individual commitment, also, is dependent on more than her own will and pleasure. This is not true of the personal commitments deriving from a personal intention, since the person with the intention is in a position unilaterally to revise or rescind that intention. This difference lends the derived commitments involved in shared intention on the plural subject account a greater stability in terms of revisability, rescindability, and release, than those involved in Bratman's or any other personal intentions account. Such stability is also possessed of course by a shared intention on the plural subject account.

There is, also, more reason to conform to a joint commitment as such than to a personal intention as such. Actions that conform to a joint commitment are owed by each party to every other. This is an additional consideration in favor of conforming to the joint commitment. Not only is conformity owed to the others but, because of this, they have the standing to make demands and issue rebukes in relation to threatened or actual non-conformity by a given party.

A second point to make in comparing the personal intentions account with the plural subject account of shared intention is this. When people have a shared intention on the plural subject account, they are likely to develop a variety of concordant personal intentions. These will arise under the guidance, so to speak, of the foundational joint commitment and the joint commitments involved in any shared sub-plans. For instance, if Will and Xenia now share the sub-plan he proposed (according to the plural subject account), and it involves his getting paint at the store, he may form the personal intention to go to the garage and start the car, as a means of fulfilling his commitment to go to the store.

If the parties have not arrived at such a shared sub-plan-perhaps they are no longer in touch - it is even more likely to be incumbent on each to form personal intentions that mesh well with the personal intentions of the other, so as appropriately to fill in any gaps in the shared master plan. As Michael Bratman has emphasized in his work on intention, most of our plans, both personal and

\footnotetext{
66 Bratman emphasizes the role of meshing personal sub-plans of the parties in achieving coordination in the service of the shared intention. In fact, as Bratman may well allow, such coordination may best be achieved, where possible, by means of the co-creation of a shared sub-plan containing meshing roles for each.
} 
shared, are partial, in that they do not specify everything that needs to be done in order that the plan be successfully carried out.

Though the plural subject account does not itself posit any particular personal intentions, then, one can predict that shared intentions on that account will be accompanied by a variety of meshing personal intentions of the parties when those parties act appropriately in light of their shared intention and any shared sub-plans they have consequently developed.

I should emphasize that in saying this I am not saying that when there is a shared intention according to the plural subject account there will be personal intentions of the type at the core of Bratman's account, that is, personal intentions 'that we $J$ '. Nor am I saying that the development of correlative personal intentions in the sense defined earlier is predictable. On the contrary, any need for commitment in that respect is already taken care of by the joint commitment at the core of the shared intention. The personal intentions that are needed, and hence predictable, are intentions to act in ways not implicitly specified by the shared intention.

Given the plural subject account, then, shared intentions are apt to play important roles emphasized by Michael Bratman as roles we understand shared intention to play, in advance of our development of an account of it (Bratman 1993, 99). In particular, they help to organize and coordinate our personal intentions and plans in ways that favor the fulfillment of the shared intention. They do this in part by providing a stable framework within which bargaining and negotiation about how things are to proceed may take place.

Bratman has argued, reasonably, that the structure of personal intentions described in his account plays these roles. It is important to note, however, that shared intentions on the plural subject account are even better suited for these roles. Shared intentions on the plural subject account are a more felicitous, because more stable framework for bargaining and negotiation and, relatedly, a more felicitous means of coordinating personal intentions and, more generally, the commitments of individuals, and keeping them on the track of the shared intention. This is because they are more stable in relation to rescission, revision, and release.

Suppose, then, that for the sake of argument one were to agree with Bratman when he says:

"Can we describe an appropriate complex from whose proper functioning would emerge the coordinated action and planning, and the relevant framework for bargaining, characteristic of shared intention? If so, we would have reason to identify shared intention with this complex." 67

Set aside his assumption that there is a 'complex' in question that is a matter of the "attitudes of each of the individual agents - attitudes that have appropriate contents and are interrelated in appropriate ways", which may or may not rule out the conditions stipulated by the plural subject account. Think of the term

67 This and the following quotation come from Bratman 1993, 100. 
'complex' as referring simply to a number of factors, possibly just one. One could then argue that since when functioning properly the plural subject complex is more efficacious in the pertinent way than a personal intentions complexhowever complicated - it has a better title to be identified with shared intention.

Of course, I do not think that the criteria of adequacy for an account of shared intention are exhausted by the tendency of shared intentions to fulfill the roles mentioned by Bratman. I agree with him that they have this tendency, and allow that it might reasonably be invoked in a full set of criteria of adequacy for shared intention. Such a full set, meanwhile, will include others that the personal intentions perspective is harder put to it to satisfy.

Before concluding this section I consider another way in which the plural subject account and a personal intentions account may be compared. Though it is not I think necessary for an adequate account of shared intention that shared intentions on that account possess features that have been highlighted by theorists as features of personal intentions, it is certainly of interest to consider whether shared intention on a given account possesses such features.

To the extent that it does not, one might seek for features that have not previously been highlighted for personal intentions but which might be common to both personal and shared intentions and significantly so. Or one might simply rest with the interesting fact that shared intentions and personal intentions have quite radically different characters. ${ }^{68}$

Bratman considers this question in relation to his own account of shared intention and gives a positive answer. One should also give a positive answer with respect to the plural subject account. Consider the following important features of intentions at the personal level emphasized by Bratman, here described somewhat cursorily and to some extent in my terms for present purposes. Personal intentions are relatively stable states of their possessors and are subject to norms of coherence and consistency both synchronic and diachronic (cf. Bratman 1993, 101). Bratman contrasts them in this respect with personal goals.

One would think that shared intentions according to the plural subject account are at least as stable as the personal intentions of individuals. And insofar as personal intentions are subject to demands for coherence and consistency, and so on, these shared intentions would appear to be subject to similar demands. If Zena and her friends share such an intention to bring peace to the world, they have reason, by virtue of that intention, to develop concordant sub-plans, both synchronic and diachronic, at both the shared and the individual level.

\section{Concluding Remarks}

I have proposed three main criteria of adequacy for an account of shared intention specifically: the disjunctive, obligation, and concurrence criteria, along with several subsidiary criteria. The plural subject account satisfies these criteria. Something that I shall not pursue here is a conjecture that I am inclined to

\footnotetext{
68 Cf. Gilbert 2002a in relation to belief, where points supposedly criterial for belief in the individual case are explored in relation to the collective case.
} 
accept: if and only if we invoke joint commitment in one way or another are we in a position to develop an account of shared intention that meets these criteria. Certainly, an account of shared intention whose core is a set of correlative personal intentions does not seem capable of satisfying any of the criteria.

Whether or not it stands as the most adequate account of shared intention it is worth having in view a joint commitment account along the lines I have proposed. For whatever we call a situation in which the conditions it stipulates obtain, that situation is likely to be of great consequence for all concerned.

This is true, indeed, of any situation in which there is a joint commitment, in which sociality and an important form of obligation come together. Whatever we jointly commit ourselves to 'do' as a body-decide, intend, believe, accept as a rule, and so on - we create for each one of us a relatively intractable, and hence relatively stable framework for his or her life, both in the short and in the longer term. ${ }^{69}$

\section{Bibliography}

Aristotle (circa 345 B.C./1998) Politics, trans. by C. D. C. Reeve, Indianapolis Bacharach, M. (2006), Beyond Individual Choice: Teams and Frames, Princeton

Bagozzi, R./U. M. Dholakia (2006), Open Source Software User Communities: A Study of Participation in Linux User Groups, in: Management Science 52, 1009-1115

Bardsley, N. (2007), On Collective Intentions: Collective Action in Economics and Philosophy, in: Synthese 157, 141-159

Bratman, M. (1987), Intentions, Plans, and Practical Reason, Cambridge

- (1992), Shared Cooperative Activity, in: Philosophical Review 101, 327-340

- (1993), Shared Intention, in: Ethics 104, 97-113

- (1999), Shared Intention and Mutual Obligation, in: M. Bratmann, Faces of Intention, Cambridge, 130-141

- (1999), Faces of Intention, Cambridge

- (forthcoming), Modest Sociality and the Distinctiveness of Intention, in: Philosophical Studies.

Davis, J. (2003), Collective Intentionality, Complex Economic Behavior, and Valuation, in: Protosociology 18, 163-183

Feinberg, J. (1970), The Nature and Value of Rights, in: Journal of Value Inquiry 4, 243-257

French, P. /H. Wettstein (2006) (eds.), Shared Intentions and Collective Responsibility, in: Midwest Studies in Philosophy 30, Boston

Gilbert, M. (1978), On Social Facts, D. Phil.thesis, Manuscript, Oxford

- (1981), Game Theory and Convention, in: Synthese 44, 41-93 (Reprinted in Gilbert 1996)

\footnotetext{
69 I have benefited from and am grateful to Anton Leist, Abe Roth, Frank Stewart, and two anonymous referees for Analyse $\mathcal{G}$ Kritik for detailed comments on various drafts of this paper. Thanks also to Thomas Smith, and to the discussants at the invited symposium on shared intention that was part of the Pacific Division American Philosophical Association meetings in Pasadena, 2008, where I presented a shorter version of this paper under the title 'Shared Intention and Personal Intentions'. A revised version of that paper will be published in an issue of Philosophical Studies devoted to selected sessions from the conference. Michael Bratman was my co-symposiast. I have appreciated the attention he has given to my work over the years, while developing his personal intentions account of shared intention.
} 
- (1987), Modeling Collective Belief, in: Synthese 73, 185-204 (Reprinted in Gilbert 1996)

- (1989), On Social Facts, London

- (1990), Walking Together: A Paradigmatic Social Phenomenon, in: Midwest Studies in Philosophy 25, 1-14 (Reprinted in Gilbert 1996)

- (1996), Living Together: Rationality, Sociality, and Obligation, Lanham

- (1997), What Is It for Us to Intend?, in: in G. Holmstrom-Hintikka/R. Tuomela (eds.), Contemporary Action Theory 2, Dordrecht, 65-85 (Reprinted in Gilbert 2000)

- (1998), In Search of Sociality: Recent Developments in the Philosophy of Social Phenomena, in: Philosophical Explorations 1, 233-241 (Reprinted in Gilbert 2000)

- (2000), Sociality and Responsibility: New Essays in Plural Subject Theory, Lanham

- (2002a), Belief and Acceptance as Features of Groups, in: Protosociology 16, 35-69

- (2002b), Collective Wrongdoing: Moral and Legal Responses, in: Social Theory and Practice 28, 167-187

- (2003), The Structure of the Social Atom: Joint Commitment as the Foundation of Human Social Behavior, in: F. Schmitt (ed.), Socializing Metaphysics, Lanham, $39-64$

- (2004), Scanlon on Promissory Obligation: The Problem of Promisees' Rights, in: Journal of Philosophy 101, 83-109

- (2006), A Theory of Political Obligation: Membership, Commitment, and the Bonds of Society, Oxford

- (2007), Searle and Collective Intentions, in: S. Tsohatzidis (ed.), Intentional Acts and Institutional Facts, Dordrecht

- (2008), Social Convention Revisited, in: Topoi 27, 5-16

- (2007), The Morality of Obedience, Manuscript, Philosophy Department, University of California, Irvine

Gold, N./R.Sugden (2007), Collective Intentions and Team Agency, in: Journal of Philosophy 104, 109-137

Grosz B./L. Hunsberger (2006), The Dynamics of Intention in Collaborative Activity, in: Cognitive Systems Research 7, 259-272

Hart, H. L. A. (1955), Are There Any Natural Rights?, in: The Philosophical Review 64, 175-191

- (1961), The Concept of Law, Oxford

Hohfeld, W. N. (1913/1964), Fundamental Legal Conceptions, New Haven

Kutz, C. (2000a), Acting Together, in: Philosophy and Phenomenological Research 61, $1-31$

- (2000b), Complicity: Ethics and Law for a Collective Age, Cambridge

Lewis, D. K. (1969), Convention: A Philosophical Study, Cambridge

MacMahon, C. (2005), Shared Agency and Rational Cooperation, in: Nous 39, 284308

Miller, S. (2005), Intentions, Ends, and Joint Action, in: Philosophical Papers 24, 5166

Rosenberg, J. (1980), One World and Our Knowledge of It, Dordrecht

Roth, A.S. (2004), Shared Agency and Contralateral Commitments, in: Philosophical Review 113, 359-410

Scanlon, T. (1998), What We Owe to Each Other, Cambridge/MA

Searle, J. (1990), Collective Intentions and Actions, in: P. R. Cohen/J. Morgan/ M. E. Pollack (eds.), Intentions in Communication, Cambridge/MA, 401-415 
Sellars, W. (1963), Imperatives, Intentions, and the Logic of 'Ought', in: G. Nakhnikian/ H. N. Castaneda (eds.), Detroit, 159-218

Sugden, R. (1993), Thinking as a Team: Toward an Explanation of Non-Selfish Behavior, in: Social Philosophy and Policy 10, 69-89

- N. Gold (2007), Theories of Team Reasoning, in: F. Peter/H.-B. Schmid (eds.), Rationality and Commitment, Oxford, 280-312.

Taylor, C. (1985), Philosophical Papers 2. Philosophy and the Human Sciences, Cambridge

Tuomela, R. (1984), A Theory of Social Action, Dordrecht

- K. Miller (1985), We-Intentions and Social Action, in: Analyse \& Kritik 7, 26-43

— / — (1988), We-Intentions, in: Philosophical Studies 53, 367-389

Vanderschraaf, P./G. Sillari (2007), Common Knowledge, in: The Stanford Encyclopedia of Philosophy: http://www.plato.stanford.edu/archieves/fall2007/entries/ common-knowledge

Velleman, D. (1997), How to Share an Intention, in: Philosophy and Phenomenological Research 57, 29-50

Verbeek, B. (2007), Rational Self-Commitment, in: F. Peter/H.-B.Schmid (eds.), Rationality and Commitment, Oxford 